El consenso y el margen de apreciación en la protección de los derechos humanos.

María Angélica Benavides Casals

páginas 295 - 310

\title{
EL CONSENSO Y EL MARGEN DE APRECIACIÓN EN LA PROTECCIÓN DE LOS DERECHOS HUMANOS***
}

\author{
María Angélica Benavides Casals***
}

\begin{abstract}
RESUMEN
Partiendo de la universalidad de los derechos humanos, este trabajo tiene por objetivo exponer la aplicación del consenso y del margen de apreciación por parte de dos tribunales internacionales (CEDH y la CIDH). La idea central es que a falta de un consenso en la comprensión del sentido y alcance de los derechos, es razonable reconocer a los Estados la posibilidad de considerar las particularidades de las distintas sociedades en la aplicación de los tratados sobre derechos humanos. Esto beneficia el progresivo compromiso adquirido por los Estados en materia de reconocimiento y protección de los derechos humanos. Además es necesario aceptar lo acertado de reconocer un núcleo esencial que conforma cada derecho humano y sus manifestaciones.

La diversidad cultural que impregna el contenido de los derechos humanos hace necesario una equilibrada aplicación de ambos criterios. Además se afirma que si bien este margen de apreciación respeta acertadamente las individualidades y particularidades de cada Estado en la aplicación de los tratados sobre derechos humanos, sus contornos no son pétreos e inamovibles y ceden o es posible que lo hagan, de acuerdo al concierto que la comunidad internacional, sea regional o universal, vaya alcanzando. Estos conciertos o acercamientos en los contenidos
\end{abstract}

* Trabajo recibido el 21 de abril de 2009, fue aprobado el 3 de mayo de este año.

** La jurisprudencia utilizada corresponde a la Corte Interamericana de Derechos Humanos y el Tribunal Europeo de Derechos Humanos y se encuentra en internet: http://www.corteidh.or.cr/ y http://www.echr.coe.int/echr. Las traducciones al castellano de las sentencias citadas son de la autora y por tanto no oficiales.

*** Abogado, Pontificia Universidad Católica de Chile. Directora Escuela de Derecho Universidad Andrés Bello. Profesora Derecho Internacional Público Universidad Andrés Bello. Doctora en Derecho Universidad del Sarre, Alemania. LL.M. EuR. Europa Institut Universidad del Sarre, Alemania. Diplomada en Integración Europea, mención en derechos humanos, Europa Institut Universidad del Sarre, Alemania. Correo electrónico: mabenavidescasals@yahoo.com. 
de los derechos y sus manifestaciones irían dando cuenta de reducciones por tanto, del ámbito de aplicación de la doctrina del margen de apreciación dando paso al consenso como criterio de interpretación. Es más fácil alcanzar estos consensos en sistemas regionales de protección de los derechos humanos y no siempre extrapolables entre estos sistemas.

\begin{abstract}
Acknowledging the universality of human rights, this article aims to show how the interpretation standards of consensus and margin of appreciation are applied by the European and Inter-American courts of human rights. Its main idea is that when consensus in the understanding of the meaning and scope of rights is lacking, it is reasonable to give the states the possibility of considering the particularities of each society when applying human rights treaties. This would benefit the progressive commitment made by states to recognize and protect human rights. It is also argued that is positive to differentiate between an essential core that makes up every human right and its manifestations

The cultural diversity behind the human rights content requires a balanced application of consensus and margin of appreciation. The latter protects the particularities of each State at applying human rights treaties without being an immovable boundary and can change and adapt to the evolution of international consensus either at a global or regional level. If the essential core of the human rights content increase, then the manifestations of such a content at the national level would diminish. In other words the scope of the margin of appreciation and their of the consensus would decrease as interpretation standard increases.
\end{abstract}

\title{
PALABRAS CLAVES
}

Consenso, Margen de apreciación, derechos humanos.

KEYWORDS

Consensus, Margin of appreciation, human rights.

\section{Introducción}

El carácter de universal de los derechos humanos es lo que ha permitido que el derecho internacional se presente como una herramienta eficaz para su protección, complementando así la función de protección del derecho nacional en esta materia.

En múltiples instrumentos internacionales sobre derechos humanos se reconoce su carácter de universal. Así en la Declaración Universal de los Derechos del Hombre se señala que "Todos los seres humanos nacen libres e iguales en dignidad y derechos y, dotados como están de 
El consenso y el margen de apreciación en la protección de los derechos humanos.

razón y conciencia, deben comportarse fraternalmente los unos con los otros" (Art. 1) ${ }^{1}$.

Esta universalidad representa por tanto parte del consenso al que los estados han llegado en materia de derechos humanos. Consenso que identificaremos en este punto sólo con un acuerdo en torno a la existencia de ciertos derechos esenciales que emanan de la naturaleza humana y cuyo reconocimiento y protección es requisito indispensable para la constitución de una sociedad internacional centrada en el desarrollo material y espiritual de la persona humana.

Si bien la comunidad internacional en los últimos 50 años se ha volcado a un trabajo cuyos resultados, exitosos algunos y otros no tanto, han dado lugar a un consenso sobre estándares mínimos de reconocimiento y protección de los derechos humanos en el ámbito convencional y consuetudinario, es fácil percibir que el mundo es actualmente no sólo dispar cultural sino que jurídicamente, en lo relativo a cuál es el contenido de los derechos reconocidos y cómo son protegidos. Por tanto, si bien el consenso en torno a la existencia de los derechos humanos es parte del derecho internacional actual, este consenso dista mucho de reflejar acabados acuerdos en el contenido y alcance de cada uno de los derechos individuamente considerados. Consecuencia de ello es en parte la generalidad con que se conciben los términos contenidos en las normas de los tratados sobre derechos humanos, la posibilidad dada en casi todos ellos de formular reservas y la falta, que por regla general se observa, de instancias jurisdiccionales convencionales obligatorias.

No es posible desconocer que una consecuencia de la falta de un amplio consenso en materia de derechos humanos en cuanto a su contenido y alcance, se manifiesta en que la jurisdicción internacional y específicamente la relativa a los derechos humanos es de excepción y además subsidiaria, y salvo la experiencia europea, el sometimiento a estas instancias es aún un elemento discrecional de los estados. Es posible discutir sobre la conveniencia o no de esta situación. Pero la realidad es que los estados, los órganos estatales de protección de derechos fundamentales, son los primeros llamados a proteger estos derechos. Y ellos actúan llenando de contenido los enunciados normativos que se encuentran en los tratados de derechos humanos desde sus muy particulares realidades y tradiciones jurídicas, aún cuando en una importante parte del mundo occidental los órganos nacionales intentan mantenerse dentro de los márgenes

En la Carta de Naciones Unidas Artículo 1: "Los Propósitos de las Naciones Unidas son: (...) 3. Realizar la cooperación internacional en la solución de problemas internacionales de carácter económico, social, cultural o humanitario, y en el desarrollo y estímulo del respeto a los derechos humanos y a las libertades fundamentales de todos, sin hacer distinción por motivos de raza, sexo, idioma o religión".

Tanto el Pacto Internacional de Derechos Económicos, Sociales y Culturales, como el Pacto Internacional de Derechos Civiles y Políticos, ambos adoptados por la Asamblea General de Naciones Unidas el 16 de diciembre de 1966, indican en su preámbulo que "(...)conforme a los principios enunciados en la Carta de las Naciones Unidas, la libertad, la justicia y la paz en el mundo tienen por base el reconocimiento de la dignidad inherente a todos los miembros de la familia humana y de sus derechos iguales e inalienables (...)" 
alcanzados en el ámbito del derecho internacional de los derechos humanos. Pero una exacta sincronía entre derecho nacional y derecho internacional de los derechos humanos no es exigible. No es conveniente ni tampoco actualmente posible para todos los países.

Ahora bien, el consenso no sólo es requisito para el nacimiento de una norma internacional que reconoce los derechos humanos. Es también un método de interpretación que permite a los órganos jurisdiccionales internacionales el determinar en un momento cómo la comunidad internacional en la que se aplica esa norma entiende el derecho en cuestión, permitiéndole establecer si ha existido o no una violación. La búsqueda que el tribunal internacional hace de la comprensión que tienen los estados de la norma convencional vaga y carente de claros contornos, tiene por tanto como resultado una interpretación guiada por el consenso de los estados en relación a la comprensión del derecho. La búsqueda de este consenso es clara en la jurisprudencia de ambos tribunales tratados en el presente trabajo. Pero particularmente y entre otras por razones de volumen de jurisprudencia, es más nítida en la del Tribunal Europeo de Derechos Humanos (TEDH).

Sin perjuicio de la búsqueda del consenso respecto del sentido y alcance del contenido del derecho, es también recurrente, y aparentemente contradictoria, la aplicación del margen de apreciación estatal en la aplicación de las normas convencionales. Pareciera ser contradictorio el permitir que los estados decidan respecto del contenido de ciertos derechos o las posibilidades de restringir su ejercicio si lo que se busca con el establecimiento de normas internacionales y órganos de supervisión es la creación de un orden general y homogéneo en sus resultados, esto es en la efectiva protección de los derechos humanos.

Lo cierto es que en la práctica de los tribunales internacionales tratados en el presente trabajo se recurre a la teoría del margen de apreciación como criterio hermenéutico. Y mal se podría sostener que el permitir un margen de apreciación de los estados al aplicar y por tanto interpretar los derechos, es incompatible con la efectiva protección de los derechos humanos, toda vez que el tribunal que lo ha aplicado por primera vez y lo continúa aplicando es el TEDH, órgano del sistema que se tiene actualmente como el más efectivo en la protección de tales derechos.

Por otra parte el permitir un margen de apreciación estatal en la interpretación y por tanto en la aplicación de las normas de derechos humanos en el orden interno, implica no sólo un adecuado equilibrio entre la soberanía estatal y el control jurisdiccional internacional ${ }^{2}$, sino también el potenciar la democracia alcanzada por los estados mediante la implementación de procesos transparentes, participativos y sujetos a control, en la creación de las normas por las que la

Peter Paczolay, "Consensus et discrétion: évolution ou érosion de la protection des droits de l'homme?" en Dialogue entre juges, Ed. ECHR, Estrasburgo, 2008, p. 113. 
El consenso y el margen de apreciación en la protección de los derechos humanos.

sociedad nacional de que se trate se regirá y la actuación de los órganos encargados de ejercer potestades públicas. Ahora bien, esto admite matices que serán más adelante abordados en este trabajo y que dicen relación con la creación paulatina de un orden público internacional en materia de derechos humanos.

Focalizarse sólo en el consenso, impidiendo un margen de apreciación de los estados para interpretar las normas de derechos humanos que aplican no sólo los dos órganos tratados en el presente trabajo sino que en primer lugar las jurisdicciones nacionales, implica la contradicción de entregar a las mayorías la determinación del contenido de los derechos ${ }^{3}$. Pertenece a la esencia de los sistemas de protección de los derechos humanos el respeto y protección de los derechos de las minorías. Y estas minorías no se identifican únicamente con la situación particular de un grupo de personas al interior de una nación sino también la particularidad de una sociedad entera organizada como estado que entiende y aplica los derechos humanos desde su específica identidad cultural y jurídica. Esto partiendo de un núcleo no disponible de cada derecho humano. Es tarea de los órganos determinar cuál es ese núcleo ${ }^{4}$.

Sin perjuicio de lo razonable de aplicar ponderadamente el consenso y el margen de apreciación como criterios de interpretación, es cuestionable el cómo los órganos jurisdiccionales internacionales encuentran el consenso. ¿Es necesario probar un consenso constituido sólidamente o basta con establecerlo por tendencias como se desprende de cierta jurisprudencia europea? ${ }^{5}$ ¿Debe el tribunal por otro lado sólo constatar la existencia de ese consenso o facilitar su nacimiento?

Partiendo del supuesto que es requisito para un efectivo sistema de protección de los derechos humanos un adecuado equilibrio entre, por una parte, el margen de apreciación entregado a los estados en la aplicación de las normas convencionales y por otro, la aplicación de un criterio de consenso para interpretar una norma convencional, se intentará exponer mediante un análisis jurisprudencial no sólo lo adecuado de la aplicación de ambos criterios, sino también de las contradicciones a que ha dado lugar dicha aplicación.

\section{1.- El consenso y el margen de apreciación según el Tribunal Europeo de Derechos Humanos}

El proceso interpretativo utilizado por el TEDH está compuesto por diversos métodos, criterios y elementos que le permiten determinar el contenido de un derecho y establecer la

Peter Paczolay, "Consensus et discrétion: évolution ou érosion de la protection des droits de l'homme?" en Dialogue entre juges, Ed. ECHR, Estrasburgo, 2008, p. 124.

Paul Martens, "Le désarrois du juge national face aux caprices du consensuseuropéen", en Dialogue entre juges, Ed. ECHR, Estrasburgo, 2008, p. 90 ss.

Murray, John, "Consensus: concordance ou hégémonie de la majorité?" en Dialogue entre juges, Ed. ECHR, Estrasburgo, 2008, p. 38. 
violación o ausencia de ella. El Tribunal aplica necesariamente la regla general de interpretación contenida en la Convención de Viena sobre el Derecho de los Tratados de 1969, toda vez que la Convención Europea de Derechos Humanos (en adelante CEDH o la Convención) es un tratado de derecho internacional y por tanto sujeta al régimen establecido en la mencionada convención. Un estudio pormenorizado de esta regla excede los márgenes de este trabajo ${ }^{6}$. Pero partiendo de la especial naturaleza de los tratados de derechos humanos ${ }^{7}$, el Tribunal aplica también criterios de interpretación que le son propios a los tratados de esta especie y que han sido desarrollados tanto por la jurisprudencia como por la doctrina internacional ${ }^{8}$. Dentro de esos criterios se encuentra el consenso y la teoría del margen de apreciación ${ }^{9}$.

Numerosa jurisprudencia del Tribunal nos muestra que con la finalidad de fijar el contenido de un derecho de la Convención en un momento determinado, el TEDH se da a la tarea de buscar entre la comunidad regida por la Convención la existencia de una comprensión uniforme del derecho en cuestión. Es decir la existencia de un consenso. Esta búsqueda puede sorprender a aquellos que estiman que un tribunal internacional debería privilegiar la mayoría de las veces la determinación independiente del sentido y alcance de los derechos a proteger. Lo que se conoce en su forma extrema como gobierno de los jueces. Si bien esto implica una interpretación autónoma de los términos convencionales, la que es utilizada acertadamente por el TEDH ${ }^{10}$, el Tribunal no aplica un único método o criterio de interpretación. Interpretar una norma obliga a llevar adelante un proceso complejo, quizás uno de los más difíciles a los que se ve enfrentado un juez internacional.

La aplicación del consenso como criterio interpretativo obedece a razones evidentes. Es la comunidad regida por las normas convencionales a aplicar la que le da vida a esas normas. Es la comunidad la que vive el derecho y determina su contenido preciso partiendo de un

6 Ver Fernández de Casadevante, Carlos, La interpretación de las normas internacionales, Ed, Aranzadi, Pamplona, 1996; Yasseen, Mustafa K. 1976. "L' interprétation des traités d'après la Convention de Vienne sur le droit des traités". Recueil des cours / Académie de Droit International de La Haye, 151, La Haya. Neuhold, Hanspeter, Die Wiener Vertragskonvention 1969, Archiv des Völkerrecht, 1971. Köck, Heribert. 1998. "Zur Interpretation völkerrechtlicher Verträge", Zeitschrift für öffentliches Recht 53.

7 Ver sentencia CIJ Barcelona Traction 1970. Corte Interamericana de Derechos Humanos, caso Hilaire contra Trinidad y Tobago, sentencia del 1 de septiembre de 2001, párr.94. Tribunal Europeo de Derechos Humanos, caso Loizidou contra Turquía, sentencia del 23 de marzo de 1995, párr. 70;

$8 \quad$ Ver Matscher, Franz, "Die Methoden der Auslegung der EMRK in der Rechtsprechung ihrer Organe" en Aktuelle Fragen zum Europarecht aus der Sicht in- und ausländischer Gelehrter, Österreichische Akademie der Wissenschaften, Viena, 1986.

$9 \quad$ Matscher, Franz, "Methods of interpretation of the Convention", en The European system for the protection of human rights, Nijhoff, Dordrecht - Boston - Londres, 1993.

10 Van der Meersch, Ganshof. Réflexions sur les méthodes d'interprétation de la Cour européenne des Droits de l'Homme: l'autorité de ses arrêts et leurs voies d'exécution, Doc. Cour (83)33, Consejo de Europa, Estrasburgo, 1983. TEDH caso Engel contra Holanda, sentencia del 8 de junio de 1976, párr. 81 y 82. 
El consenso y el margen de apreciación en la protección de los derechos humanos.

núcleo inderogable ${ }^{11}$. La sociedad evoluciona, lo que se manifiesta entre otros en actos legislativos, ejecutivos y judiciales. Pero cuando el tribunal no ha encontrado un consenso en torno al sentido y alcance del derecho, en ocasiones se ha aplicado lo que se conoce como el margen de apreciación.

En el ámbito del derecho internacional de los derechos humanos esta teoría ha sido utilizada por primera vez por el Tribunal Europeo de Derechos Humanos. Ella es el resultado de un desarrollo jurisprudencial necesario. Para comprender su significado y justificar su aplicación es necesario partir desde la premisa que si bien el sistema europeo se basa en la búsqueda de un orden europeo común cuyas bases más elementales ya existen ${ }^{12}$, las particularidades de los estados no son desconocidas allí donde un consenso falta. El equilibrio entre el respeto a las diversidades jurídicas y sociales, la falta de consenso y la efectiva protección de los derechos humanos es lo que ha llevado al TEDH a aplicar el margen de apreciación.

Si bien la creación de un orden público europeo constituye una finalidad del TEDH ${ }^{13}$, la aplicación del margen de apreciación da a entender que el desarrollo de este orden es paulatino y no forzado por el Tribunal, esperando el momento oportuno para establecer parámetros homogéneos. La creación de este orden público europeo, y que excluye por tanto la aplicación del margen de apreciación en los ámbitos en los que se da, ha sido plasmada en recurrente jurisprudencia ${ }^{14}$.

La teoría del margen de apreciación nos indica en definitiva que allí donde no existe un mínimo común europeo para entender de una determinada manera el contenido de un derecho, se abre para el estado un margen de acción que le permite fijar de acuerdo a circunstancias jurídicas, sociales y culturales el contenido y alcance de ciertos derechos, a la espera por parte del TEDH de poder encontrar elementos nuevos que le permitan establecer contenidos que se integrarán al orden público europeo y serán por tanto aplicables a todos los estados miembros del Consejo de Europa por igual.

Sin perjuicio de esto, es posible descubrir en la jurisprudencia del Tribunal que la aplicación tanto del consenso como del margen de apreciación no presenta siempre una coherencia absoluta.

11 Sin perjuicio de la postura de algunos que consideran que así como la evolución natural sería ir ampliando los márgenes del contenido del derecho, existiría la posibilidad que se de un proceso regresivo.

12 Democracia, estado de derecho, respeto a los derechos humanos.

13 Trindade, Antonio. 2004. "Le développement du droit international des droits de l'homme à travers l'activité et la jurisprudence des Cours européenne et interamericaine des droits de l'homme". Revue universelle des droits de l'homme, vol. 16, $\mathrm{n}^{\circ}$ 5-8, p. 177.

14 TEDH, caso Tyrer contra Gran Bretaña, sentencia del 25 de abril de 1978; caso Loizidou contra Turquía, sentencia del 23 de marzo de 1995; caso Bancovic contra Bélgica y otros, sentencia del 12 de diciembre de 2001. 
Esto es sin perjuicio de que se podría sostener, no sin fundamento, que parte de este orden público es precisamente el respeto a las diversidades culturales, sociales y jurídicas.

Los ámbitos en los que el TEDH ha aplicado el margen de apreciación a falta de consenso se pueden clasificar en tres: en la ponderación de las circunstancias que ameritan decretar estado de excepción y por tanto autorizan al estado a restringir el ejercicio de ciertos aspectos de los derechos, en segundo lugar en las posibilidades de limitar el ejercicio de los derechos contenidos en los artículos 8, 9, 10 y 11 del CEDH, y en tercer lugar en el contenido y alcance de ciertos derechos o aspectos de ellos.

\section{1.- Estado de excepción del artículo 15 de la CEDH}

El artículo 15 de la Convención permite en caso de guerra o de otro peligro público que amenace la vida de la nación, que el estado adopte "medidas que deroguen las obligaciones previstas en el presente Convenio en la estricta medida en que lo exija la situación, y supuesto que tales medidas no estén en contradicción con las otras obligaciones que dimanan del derecho internacional". Para la valoración de las situaciones que fundamentan sea decretado un estado excepción el Tribunal recurrió en un comienzo al margen de apreciación. En el caso Irlanda contra Gran Bretaña ${ }^{15}$ donde se discutían, en el marco del ejercicio de poderes de la autoridad inglesa derivados del declarado estado de excepción, la aplicación de las llamadas cinco técnicas de interrogatorio, el Tribunal señaló expresamente que el estado responsable de la "vida de la nación" está en mejor posición que el juez internacional para determinar si un peligro público la amenaza, debido a que se encuentra en "contacto directo y constante con la realidad presente en un momento determinado" y puede por tanto "pronunciarse sobre la presencia de un peligro así como sobre la naturaleza y extensión de las derogaciones necesarias para hacerle frente. El artículo 15 inc. 1 les otorga en esta materia un amplio margen de apreciación"16.

Sin embargo el TEDH ha ido progresivamente desarrollando un control al ejercicio de esta facultad concedida a los estados. Es así como en casos posteriores ${ }^{17}$ el TEDH demanda para sí la competencia de revisar las condiciones que el estado ha tenido en consideración para aplicar el artículo 15 de la CEDH. Además el Tribunal examina si las medidas fueron las estrictamente necesarias de acuerdo a la situación. El TEDH si bien hace suyo el razonamiento del caso precedentemente citado, señala que la facultad del estado no es ilimitada en este ámbito y que el Tribunal tiene competencia para decidir si se ha excedido la estricta medida de las exigencias que plantea la crisis. Por tanto el margen de apreciación se sujeta a un control europeo. La Corte debe atribuir el peso que corresponda a factores pertinentes tales como la

Sentencia del 18 de enero de 1978.

Párr. 207 de la sentencia.

Caso Brannigan y McBride contra Gran Bretaña, sentencia del 26 de mayo de 1993. 
El consenso y el margen de apreciación en la protección de los derechos humanos.

naturaleza de los derechos afectados por la derogación, la duración del estado de excepción y las circunstancias que lo han originado ${ }^{18}$.

En este ámbito no es aplicado el consenso. La razón está expuesta por el Tribunal y no contradicha posteriormente, señalando que el estado está "en contacto directo y constante con la realidad presente en un momento determinado". Y cuando el TEDH limita el margen de apreciación estatal no lo hace porque haya encontrado un consenso que será considerado parte del orden público europeo. Lo limita porque con el paso del tiempo el Tribunal considera que siendo el guardián de los derechos humanos en el ámbito europeo debe velar para que la libertad en la interpretación de circunstancias de hecho que fundamenten que sea decretado un estado de excepción, no sea entregado a la arbitrariedad del estado.

Por tanto el Tribunal acertadamente no aplica el consenso, acercándose más bien a la utilización de un criterio de proporcionalidad interpretativo.

\section{2.- Restricciones permitidas al ejercicio de los derechos de la CEDH}

La segunda aplicación que el TEDH ha realizado del margen de apreciación entregado a los estados en la aplicación de la Convención está relacionada con la posibilidad que otorgan ciertos artículos de establecer restricciones legales fundados en la "seguridad nacional, la seguridad pública, el bienestar económico del país, la defensa del orden y la prevención de las infracciones penales, la protección de la salud o de la moral, o la protección de los derechos y las libertades de los demás" y en la medida que la injerencia sea necesaria en una sociedad democrática ${ }^{19}$.

Si bien al estado se le reconoce un margen para apreciar las circunstancias de facto y poder restringir las libertades y derechos de esos derechos, el TEDH lleva a cabo un control relativo en primer lugar a si las medidas adoptadas por el estado son necesarias dentro de una sociedad democrática, en segundo lugar la compatibilidad con los derechos reconocidos y finalmente la conformidad de las restricciones con el orden público europeo. Un ejemplo de este característico esquema de control lo encontramos en el caso Bladet Troms $\emptyset$ und Stensaas contra Noruega ${ }^{20}$. El caso se refiere a artículos publicados en un diario noruego relativo a la caza de focas. En los artículos se habría informado sobre crueles actos cometidos por los cazadores en focas vivas. La jurisdicción noruega impidió la circulación del periódico debido al supuesto carácter difamatorio de las publicaciones. El TEDH reafirmando que la reputación

\footnotetext{
18 Párr. 42 y s. de la sentencia.

19 Artículos 8 (Derecho al respeto a la vida privada y familiar), 9 (Libertad de pensamiento, de conciencia y de religión), 10 (Libertad de expresión) y 11 (Libertad de reunión y de asociación).

20

Sentencia del 20 de mayo de 1999.
} 
es un límite a la libertad de información, sostiene que la prensa puede recurrir a una cierta exageración para llamar la atención sobre temas que son de interés en sectores de la sociedad. El TEDH reconoce el margen de apreciación de los estados para restringir el derecho según el artículo 10 inc. 2, pero determina que la sanción impuesta en el caso concreto (prohibición de circulación del medio) era desproporcionada y no necesaria en una sociedad democrática.

Por tanto al igual que en el supuesto del artículo 15 de la Convención previamente expuesto, los estados se encuentran en la mejor posición, según el TEDH, para adoptar medidas legales que restrinjan el ejercicio de los derechos sin que esto constituya una violación a la Convención. Así lo constata expresamente el Tribunal en el caso Buckley contra Gran Bretaña ${ }^{21}$, "estando en contacto directo y permanente con las fuerzas vitales del país, las autoridades nacionales están en principio mejor situadas que una la jurisdicción internacional para evaluar las necesidades y el contexto local"22.

Ciertos ámbitos se presentan como particularmente influenciados por las especificidades propias de cada sociedad. Tal es el caso de la moral ${ }^{23}$. Es así como en muchos casos relativos a estos ámbitos no existe un mínimo común extrapolable a todos los estados parte de la CEDH y por tanto no es posible interpretar de una forma única un derecho determinado de la Convención, haciéndose necesario que cada estado dentro de sus muy especiales aproximaciones en materia moral aprecie en forma individual el estado y desarrollo de su sociedad fijando las restricciones que la Convención permite al ejercicio de ciertos derechos.

\section{3.- La determinación del contenido del derecho}

Una tercera aplicación de la doctrina del margen de apreciación o consenso en su caso se refiere al grado de autonomía entregada al estado para determinar ya no las restricciones autorizadas por la CEDH al ejercicio de ciertos derechos o a la ponderación de los hechos que fundamentan sea decretado un estado de excepción, sino al contenido mismo de los derechos de la Convención.

Dentro de la jurisprudencia desarrollada por el TEDH aquí sólo abarcaremos dos áreas. El derecho a contraer matrimonio (artículo 12) en coordinación con el derecho a una vida familiar (artículo 8) y el derecho a la vida (artículo 2).

\footnotetext{
Sentencia del 25 de septiembre de 1996.

Párr. 75 de la sentencia.

Ver caso Handyside contra Gran Bretaña, sentencia del 7 de diciembre de 1976 párr. 48 y la evolución de la jurisprudencia del TEDH con el caso Sunday Times contra Gran Bretaña, sentencia del 26 de abril de 1979, párr. 49; caso Wingrove contra Gran Bretaña, sentencia del 25 de noviembre de 1996, párr. 58; ; caso Fretté contra Francia, sentencia del 26 de mayo de 2002, párr.. 40.
} 
El consenso y el margen de apreciación en la protección de los derechos humanos.

En el caso Cossey contra Gran Bretaña ${ }^{24}$, un transexual, persona nacida hombre que se sometió a una operación de cambio de sexo en 1974, intentó contraer matrimonio con un varón, trámite para el cual necesitaba presentar un certificado de nacimiento en el que figuraba como de sexo masculino, razón por la cual le fue negado el trámite del matrimonio, ya que según la legislación inglesa dicha institución es entre un hombre y una mujer, lo que se acredita con los documentos de la fecha del nacimiento. Ante la Corte se alega violación del artículo 8 (derecho al respeto de la vida privada y familiar) y artículo 12 (derecho a contraer matrimonio). El TEDH no encuentra elementos para aplicar una solución basada en el consenso europeo ya que no sería posible sostener que el concepto tradicional de matrimonio heterosexual con definición biológica del sexo se ha abandonado en todos los estados. Y por tanto los estados disfrutan de un margen de apreciación para regular el ejercicio de este derecho ${ }^{25}$.

Posteriormente en el caso Goodwin contra Gran Bretaña ${ }^{26}$, el TEDH no desconociendo su jurisprudencia anterior en orden al margen de apreciación de los estados en este ámbito, señala que su aplicación se ha reducido, pero no producto del nacimiento de un consenso europeo en esta materia nacido en el tiempo que media entre las anteriores sentencias y este caso en cuestión. El Tribunal no desconociendo que el derecho al matrimonio reconocido en la Convención es una institución heterosexual, decide que las formas de determinación del sexo han variado con el tiempo y ya no es posible sostener que sea una determinación puramente biológica. Por otra parte señala que el artículo 12 garantiza el derecho fundamental de un hombre y una mujer de contraer matrimonio y fundar una familia. Señala que el fundar una familia no es condición del derecho a contraer matrimonio y que la incapacidad de una pareja para concebir o criar un hijo no bastaría para privarles del derecho a contraer matrimonio. El Tribunal indica que hoy no es posible "continuar admitiendo que estos términos implican que el sexo debe ser determinado según criterios puramente biológicos (...). Desde la adopción de la Convención la institución del matrimonio ha estado profundamente afectada por la evolución de la sociedad y los progresos de la medicina y la ciencia han originado cambios radicales en el ámbito de la transexualidad. La Corte ha constatado en el terreno del artículo 8 de la Convención que la no concordancia de los factores biológicos en un transexual operado no podría constituir un motivo suficiente que justifique la negativa al reconocimiento jurídico del cambio de sexo (...). Otros factores deben ser tomados en consideración: el reconocimiento de la comunidad médica y las autoridades sanitarias en los estados parte del estado médico de confusión sobre la identidad sexual, la oferta de tratamientos incluida la intervención quirúrgica, los que permiten a la persona afectada acercarse al sexo al cual siente pertenecer, y que adopte el rol social de su nuevo sexo. La Corte nota también que la redacción del artículo 9 de la Carta

Sentencia del 27 de septiembre de 1990. Anteriores sentencias en este sentido: caso Rees contra Gran Bretaña, sentencia del 17 de octubre de 1986 y caso Sheffield contra Gran Bretaña, sentencia del 30 de julio de 1998. Párr. 103 de la sentencia. Sentencia del 11 de julio de 2001. 
de los Derechos Fundamentales de la Unión Europea adoptada recientemente se aparta - y esto no puede haber sido sino deliberado - del artículo 12 de la Convención excluyendo la referencia al hombre y a la mujer. (...). En efecto, esto llevaría a concluir que el abanico de opciones abiertas a un Estado contratante puede llegar hasta prohibir prácticamente el ejercicio del derecho a casarse. El margen de apreciación no puede ser tan amplio. Si le corresponde al Estado determinar, particularmente, las condiciones que debe cumplir un transexual que reivindica el reconocimiento jurídico de su nueva identidad sexual para establecer que su conversión sexual se ha producido y en las que un matrimonio anterior deja de ser válido, o incluso las formalidades aplicables a un futuro matrimonio, (por ejemplo las informaciones a entregar a los futuros esposos), la Corte no ve ninguna razón que justifique para que los transexuales sean privados bajo toda circunstancia del derecho de casarse"27.

El Tribunal pretende, desde nuestro punto de vista, que se otorgue al parecer, el carácter de consenso europeo a la discusión médica existente sobre la determinación del sexo. La verdad es que esto no ha dejado de ser sin embargo una discusión y dista mucho de ser un consenso. Aquí parece que el Tribunal intenta una construcción del consenso y no un reconocimiento de éste ${ }^{28}$.

Por otro lado pretende atribuir también, al parecer, el carácter de consenso en esta materia a la Carta de los Derechos Fundamentales mencionada, señalando que es de suponer que la exclusión del elemento sexo en el reconocimiento del derecho al matrimonio indica que esta omisión no pudo haber sido deliberada. Hubiese sido interesante que el TEDH hubiera expuesto parte de los trabajos preparatorios de esa Carta, que de existir estos trabajos en ese punto, fundamentaran semejante interpretación. O que al menos recurriese a algún otro medio de verificación de su postura. Por lo demás la mencionada Carta es un instrumento de la Unión Europea cuyos miembros no corresponden al del Consejo de Europa. No se trata pues de un instrumento nacido al interior de esta organización internacional y por tanto no puede representar un consenso al interior del Consejo de Europa.

De acuerdo al artículo 31 número 3 letra c de la Convención de Viena sobre el Derecho de los Tratados, para la interpretación debe tenerse en cuenta junto con el contexto como uno de los tres elementos de la regla general del artículo 31 inciso primero, toda norma pertinente de derecho internacional aplicable entre las partes. De esto no puede concluirse que un instrumento regional de alcance por tanto limitado, pueda constituirse como una norma aplicable entre las partes, ya que no todo miembro del Consejo de Europa es miembro de la Unión Europea. Si bien el mencionado artículo indica que el derecho internacional obedece a una coherencia y

\footnotetext{
27 Párr. 103 de la sentencia.

28 Ver Murray, John. 2008. “Consensus: concordance ou hégémonie de la majorité?” en Dialogue entre juges, ECHR, Estrasburgo, p. 38.
} 
El consenso y el margen de apreciación en la protección de los derechos humanos.

debe ser dentro de esa coherencia interpretado, y consecuencia de esto es posible sostener que ciertos tratados pueden ser aplicados a estados que no los han ratificado, esto corresponde más bien a instrumentos con vocación universal, como los nacidos al interior de UN o a costumbre internacional, y no a instrumentos estrictamente regionales como la mencionada Carta. Nuestro interés en la crítica de esta sentencia, revolucionaria por lo demás, consiste en la falta de rigor del Tribunal en la aplicación, o más bien en la falta de aplicación, de elementos interpretativos contundentes que lleven a deducir la existencia de un consenso europeo que restringa el margen de apreciación previamente reconocido a los estados del Consejo de Europa en el reconocimiento del matrimonio entre transexuales.

También el TEDH ha invocado el margen de apreciación de los estados para la aplicación de la Convención en el ámbito interno en el caso del derecho a la vida. El caso Vo contra Francia ${ }^{29}$ trata de un aborto practicado erróneamente en la persona de una mujer embarazada de cinco meses, quien tenía el mismo nombre de otra a la que sí debía practicársele el procedimiento, y donde el problema principal se traducía en definir si el embrión es o no titular del derecho a la vida contenido en el artículo 2 de la CEDH. El Tribunal determina que "resulta que el punto de partida del derecho a la vida emana del margen de apreciación de los estados que la Corte tiende a considerar que le debe ser reconocido a los estados en este campo. Las razones que llevan a la corte a esta constatación son por una parte que la solución para dicha protección no se encuentra en el seno de la mayoría de los estados parte y particularmente en Francia, donde la cuestión ha suscitado debate, y por otro lado, que no existe ningún consenso europeo sobre la definición científica y jurídica del comienzo de la vida"30.

Es así como a falta de consenso europeo sobre el punto, sería el estado nacional el que define si el embrión es o no titular del derecho a la vida según esta sentencia. Una opinión crítica a esta decisión la presenta el voto de minoría del juez G. Ress, quien afirma que el artículo 2 se aplica a la vida del no nacido. El magistrado sostiene que podría haber una discusión sobre las diferencias en cuanto al nivel de protección del embrión y del nacido. Esto sin embargo no puede conducir a la conclusión que es imposible responder en abstracto a la pregunta sobre si el embrión es una persona en los términos del artículo 2 de la Convención. Según él ambos sujetos (la madre y el embrión) son dos "seres humanos" diferentes que deben ser protegidos cada uno por separado. Además los estados donde se admite el aborto han enfrentado problemas constitucionales al legislar sobre el tema. Esto sólo se entiende desde la perspectiva que el feto posee vida humana. De lo contrario estas leyes no habrían sido necesarias.

Nos parece contradictoria la aplicación del consenso y del margen de apreciación en estos dos ámbitos precedentemente señalados. Por un aparte y sin mayores fundamentos 
hermenéuticos se restringe el margen de apreciación en materia de transexuales y matrimonio hasta hacer desaparecer este margen. Y por otro lado no establece el Tribunal un consenso en materia ya no del derecho al aborto, sino a que si existen leyes en este sentido es porque precisamente existe un consenso entre los estados que el no nacido si es sujeto de derechos y por esto fueron necesarias estas leyes. La determinación que el no nacido cae dentro del ámbito del artículo 2 de la Convención implica desde luego problemas con estas leyes internas que autorizan este procedimiento quirúrgico. Pero constituye a la vez una simple constatación en orden a que si existen las leyes que permiten el aborto, existe por tanto un derecho del no nacido. Esta constatación tiene su base precisamente en esas leyes de aborto: su existencia da cuenta del consenso al interior de las sociedades europeas que el no nacido es titular del derecho. El cómo esta constatación por parte del Tribunal repercutiría en las legislaciones nacionales corresponde a otra discusión.

Este tipo de razonamientos del TEDH da cuenta más bien de haberse guiado más por lo políticamente correcto, considerando el contexto europeo, que por consideraciones estrictamente jurídicas.

\section{2.- El consenso y el margen de apreciación según la Corte Interamericana de Derechos Humanos.}

Dos son las razones que justifican que la Corte Interamericana de Derechos Humanos (en adelante la Corte o CIDH) no haya profundizado particularmente en la teoría del margen de apreciación. Desde un punto de vista cuantitativo la jurisprudencia de la Corte es considerablemente menor a la del TEDH. Por tanto las oportunidades para pronunciarse al respecto son menores ${ }^{31}$. Y por otro lado la jurisprudencia de la Corte tiende al universalismo ${ }^{32}$. A diferencia del TEDH que ha elaborado la teoría del orden público europeo y de acuerdo a él, entre otros, aplica o no el consenso y el margen de apreciación de los estados, la Corte por su parte no ha elaborado una teoría de un orden público propiamente interamericano, tendiendo más bien a la universalidad y a ver un consenso universal aplicado a su jurisprudencia, al utilizar expresiones tales como el corpus iuris internaciona ${ }^{33}$.

Para ciertos autores el reconocimiento del margen de apreciación presupondría la existencia

Las razones para esto no radican en que su competencia la ejerce desde hace menos años que el TEDH, sino más bien en que no existe a diferencia del sistema europeo un recurso individual ante la Corte y en el hecho que su jurisdicción es voluntaria.

32 Opinión Consultiva "Otros Tratados" Objeto de la Función Consultiva de la Corte (art. 64 Convención Americana sobre Derechos Humanos). Opinión Consultiva OC-1/82 del 24 de septiembre de 1982. Serie A No. 1. Párr. 40.

33 Ejemplo de esto es el caso Comunidad Indígena Yakye Axa Vs. Paraguay sentencia del 17 de junio de 2005 en el que se discutían las condiciones de vida de la comunidad indígena Yakye Axa y la Corte con el objeto de tener como base un parámetro para apreciar estas condiciones utiliza la expresión corpus iuris internacional. 
El consenso y el margen de apreciación en la protección de los derechos humanos.

de una democracia inexistente en la mayoría de los estados ${ }^{34}$. Este último es un argumento rebatible. Como se expresó precedentemente, una democracia presupone una diversidad que no puede tener como resultado que en cada estado se reconozcan igualmente el contenido de ciertos derechos. Es precisamente la diversidad el resultado de un sistema democrático y es esa sociedad democrática la que debe velar por diversas formas de comprender el contenido de ciertos derechos.

La realidad es que atendida quizás la escasa jurisprudencia de la CIADH, ésta no ha tenido oportunidad de desarrollar en profundidad la teoría del margen de apreciación y tampoco un acabado concepto de consenso interamericano ${ }^{35}$.

\section{Conclusiones}

Si bien la universalidad de los derechos humanos ha sido positivamente reconocida por numerosos instrumentos internacionales, al examinar las instancias de control, nos damos cuenta que los órganos jurisdiccionales responden a esfuerzos regionales ${ }^{36}$. Esto debido a que en comunidades más pequeñas es posible lograr progresivamente mayores niveles de acuerdo en cuanto al contenido de los derechos, los que debido precisamente a falta de acuerdo inicial en cuanto a su sentido y alcance son tan vagamente concebidos. Estos acuerdos que las instancias jurisdiccionales regionales deberían ir constatando son manifestación del consenso llegado al interior de la comunidad de que se trate. Y en la medida que ese consenso no se alcance es no sólo razonable sino que necesario reconocer un margen de apreciación a los estados en la aplicación de la convención de que se trate. Esta idea ha sido claramente recogida por el TEDH. No estamos seguros que en el sistema interamericano se recorra este mismo camino. El tiempo dirá cuál es el rumbo que la Corte adoptará. Sin embargo es necesario señalar que precisamente la particularidad de las sociedades nacionales y los consensos regionales a los que pueden llegar en torno al contenido de un derecho es lo que hace más efectivos los sistemas regionales de derechos humanos. El TEDH lo ha entendido así y ha acuñado la expresión orden público europeo y en recurrente jurisprudencia ha destacado el perfil estrictamente regional del sistema europeo ${ }^{37}$. Una simple extrapolación de los avances alcanzados en el ámbito europeo al interamericano no parece razonable en el estado actual del desarrollo de los derechos humanos. Esto deja a salvo sin embargo que el derecho internacional de los derechos humanos debe tender progresivamente a materializar la universalidad de estos derechos en el contenido de ellos y su protección. Pero todo tiene su momento.

34 Trindade, Antonio, El derecho internacional de los derechos humanos en el siglo XXI, Editorial Jdca. De Chile, 2006, p. 390.

35 Ver caso Yatama contra Nicaragua, sentencia del 23 de junio de 2005, párr. 100.

36 Hasta el momento la única excepción es la Corte Penal Internacional. Y de todos modos su competencia deriva de la declaración de sometimiento que realizan los estados.

37 TEDH caso Bancovic contra Bélgica y otros, admisibilidad del 12 de diciembre de 2001, párr. 80. 
Respecto a la aplicación que han realizado ambos órganos jurisdiccionales, en especial el europeo por razones de más oportunidades para pronunciarse al respecto, del margen de apreciación y del consenso como criterios hermenéuticos, es deber decir que no siempre esta aplicación ha sido coherente particularmente en el ámbito europeo. El margen de apreciación ha sido particularmente aplicado en ámbitos morales y religiosos. Ahora bien, esta aplicación ha sido zigzagueante. Esto ha conducido en el sistema europeo a desconcertantes resultados. La mayoría de los estados europeos establecen un derecho de aborto sujeto a condiciones diversas, pero no por eso el TEDH pudo descartar que el no nacido no sea titular del derecho a la vida. Simplemente evadió fallar al respecto, lo que no deja de dejarnos perplejos si es el derecho sin el cual ningún otro puede existir, sin perjuicio que existan legislaciones que lo contemplan. Por otro lado la mayoría de los estados europeos no contempla una legislación referente al matrimonio de transexuales, pero eso no impidió al TEDH interpretar la institución del matrimonio, como lo ha venido haciendo desde su creación, como una institución heterosexual, pero desde el 2002 estableciendo que es posible que el sexo sea determinado por otras razones no exclusivamente biológicas.

Ponderar adecuadamente y con criterios claros y razonables cuándo y por qué existe la posibilidad para los estados de aplicar el margen de apreciación o excluirlo aplicando el consenso, se configura como un desafío tanto para las instancias internacionales como para la doctrina. 